\title{
VARIETIES OF DEMOCRACY IN SCIENCE POLICY1
}

\author{
Erik Weber \\ Centre for Logic and Philosophy of Science \\ Ghent University (UGent) \\ Blandijnberg 2, B-9000 Gent, Belgium \\ Erik.Weber@UGent.be
}

\section{Introduction}

In Science, Truth and Democracy Philip Kitcher distinguishes four forms of science policy: internal elitism, external elitism, vulgar democracy and enlightened democracy. In this chapter, I argue that Kitcher's arguments against elitism fail to show that elitism must be eliminated completely (i.e. they do not entail that all decisions about science policy should be taken democratically) and that his argument against vulgar democracy is unsound. I show that Kitcher has two characterizations of vulgar democracy, and that his argument against vulgar democracy is invalid under both characterizations. Then I argue that Kitcher's argument against vulgar democracy is in fact an argument against direct democracy and in favour of representative democracy. But that leaves open many options, especially with respect to the main topic (viz. the degree to which scientists should be involved in the democratic decision processes concerning science policy) for which Kitcher introduced the distinction between vulgar and enlightened democracy. Finally, the last section of this chapter is a constructive rather than critical one: based on my analysis of Kitcher's work, I formulate some proposals for implementing a democratic science policy.

\section{Kitcher's views on the aims of science}

In my criticism of Kitcher's proposals concerning science policy, I start from a view on the aims of science which is identical to his which is why I start with a summary of these views.

2.1 Let us define unrestricted intentional realism as the view on the aims of science which maintains that (i) the world has a mind-independent structure, and (ii) the aim of science is to describe this structure in a systematic and complete way. There is an obvious objection to unrestricted intentional realism. Philip Kitcher gave a version of this objection in The Advancement of Science:

Truth is very easy to get. Careful observation and judicious reporting will enable you to expand the number of truths you believe. Once you have some truths, simple logical, mathematical, and statistical exercises will enable you to acquire lots more.... The trouble is that most of the truths that can be acquired in these ways are boring. Nobody is interested in the minutiae of the shapes and colors in your vicinity, the temperature fluctuations in your microenvironment, the infinite number of disjunctions you can generate with your favorite true statement as one disjunct, or the probabilities

1 I thank Jeroen Van Bouwel and Rogier De Langhe for their comments on draft versions of this paper. 
of the events in the many chance setups you can contrive with objects in your vicinity. What we want is significant truth. (1993, p. 94)

I agree with Kitcher that objections like this one make unrestricted intentional realism untenable: we need restrictions on what is investigated and what not. The question then is: which restrictions?

In Science, Truth and Democracy, Philip Kitcher formulates the argument against unrestricted intentional realism as follows:

Nobody should be beguiled by the idea that the aim of inquiry is merely to discover truth, for, as numerous philosophers have recognized, there are vast numbers of true statements it would be utterly pointless to ascertain. The sciences are surely directed at finding significant truths. But what exactly are these? (2001, p. 65)

Kitcher's answer to the question at the end of the quote is double. On the one hand, there is "practical significance":

One possible answer makes significance explicitly relative - the significant truths for a person are just those the knowledge of which would increase the chance she would attain her practical goals. Or you could try to avoid relativization by focusing on truths that would be pertinent to anyone's projects - the significant truths are those the knowledge of which would increase anyone's chance of attaining practical goals. (2001, p. 65)

\section{But for Kitcher there is more:}

Neither of these is at all plausible as a full account of scientific significance, and the deficiency isn't just a result of the fact that both are obviously rough and preliminary. Linking significance to practical projects ignores areas of inquiry in which the results have little bearing on everyday concerns, fields like cosmology and paleontology. Moreover, even truths that do facilitate practical projects often derive significance from a different quarter. Surely the principles of thermodynamics would be worth knowing whether or not they helped us to build pumps and engines (and thereby attain further goals). Besides the notion of practical significance, captured perhaps in a preliminary way by the rough definitions given above, we need a conception of "theoretical" or "epistemic" significance that will mark out those truths the knowledge of which is intrinsically valuable. (2001, p. 65).

Kitcher is certainly not the only philosopher defending this kind of sophisticated pragmatism that leaves room for "intrinsically valuable knowledge". Carl Hempel started his famous article 'Aspects of Scientific Explanation' with the following remarks on the aims of science:

Among the many factors that have prompted and sustained inquiry in the diverse fields of empirical science, two enduring human concerns have provided the principal stimulus for man's scientific efforts.

One of them is of a practical nature. Man wants not only to survive in the world, but also improve his strategic position in it. This makes it important for him to find reliable ways of foreseeing changes in his environment and, if possible, controlling them to his advantage.

The second basic motive for man's scientific quest is independent of such practical concerns; it lies in his sheer intellectual curiosity, his deep and persistent desire to know and to understand himself and his world. (1965, p. 333).

Another example of this sophisticated pragmatism can be found in the epilogue of Larry Laudan's Progress and its Problems: 
If a sound justification for most scientific activity is going to be found, it will eventually come perhaps from the recognition that man's sense of curiosity about the world and himself is every bit as compelling as his need for clothing and food. Everything we know about cultural anthropology points to the ubiquity, even among "primitive" cultures barely surviving at subsistence levels, of elaborate doctrines about how and why the universe works. The universality of this phenomenon suggests that making sense of the world and one's place in that world has deep roots within the human psyche. By recognizing that solving an intellectual problem is every bit as fundamental a requirement of life as food and drink, we can drop the dangerous pretense that science is legitimate only in so far as it contributes to our material well-being or to our store of perennial truths. $(1977$, p. 225)

2.2 The view presented in Section 2.1 is prima facie attractive: it is not too narrow (science does not have to be practically useful) and not too wide (science has to relate to everyday human concerns, so it must be practically or theoretically useful). In my criticisms of Kitcher's views on science policy, I will start from a similar view on the aims of science. However, my implementation of epistemic significance will be broader than Kitcher's implementation. Kitcher uses the idea of "natural human curiosity" to clarify what epistemic significance is:

[T]he sciences ultimately obtain their epistemic significance from the broad questions that express natural human curiosity $(2001$, p. 81$)$.

Hempel also refers to an inborn human curiosity (cf. the quote above). In my criticism of Kitcher's views, and also in Section 5, I combine the idea of inborn human curiosity with other ways to justify research that is not practically significant.

\section{Kitcher's arguments against elitism}

Having summarized Kitcher's view on the aims of science, we can now turn to his proposals concerning which institutional framework for science policy is the most conducive to achieve these aims.

3.1 In chapter 10 of Science, Truth and Democracy Philip Kitcher distinguishes four forms of science policy: internal elitism, external elitism, vulgar democracy and enlightened democracy. His definitions of the first two institutional arrangements are:

One, internal elitism, consists in decision-making by members of scientific subcommunities. A second, external elitism, involves both scientists and a privileged group of outsiders, those with funds to support the investigations and their ultimate applications (call these people "paymasters"). (2001, p. 133)

His opinion on how decisions are actually made, is this:

I take it that the status quo in many affluent democracies is a situation of external elitism that groups of scientists constantly struggle to transform into a state of internal elitism. (2001, p. 133)

In Kitcher's view Francis Bacon (with his New Atlantis) was the first defender of elitism:

The first report on science policy was written as fable. In New Atlantis, left incomplete after his death, Bacon offered a tale about the crew of a sailing ship, who, after various disasters, find a haven in the island of Bensalem. Here the mariners are treated with great hospitality, and they are surprised by the wisdom, generosity, and incorruptibility of the island's government. Liberality and 
fair-dealing are founded on the institution of an elite group of investigators, the members of Salomon's House who seek "the knowledge of causes, and the secret motions of things." In the terms l've been using, they aim to achieve both epistemically and practically significant truths, and they are very clear about the character of both. $(2001$, p. 137)

The work of Salomon's house is carried forward by coordinating autonomous decisions made by the members in discussion with one another. At various stages, they confer to plan the next steps to be taken (following the method for individual inquiries Bacon outlined in many places). The fellows decide what to do, what to publish, what to keep secret, and what applications to make. So we are offered an explicitly elitist vision of well-ordered science, one that takes an objectivist vision of the good that which inquiry aims. There are certain things which it is good for human beings to know because it will relieve their curiosity, certain things which it is good to know because applying the knowledge will contribute to human welfare. The wise inquirers understand these things and thus bestow all kinds of benefits on their society. (2001, pp. 137-138)

The second part of the quote reveals an important characteristic of Kitcher's argument against elitism: he assumes that elitism can only be justified by invoking an objectivist vision on what practically significant and epistemically significant truths are.

3.2 According to Kitcher, one of the core philosophical questions with respect to science policy is "what are good ways for a community to organize inquiry if they want to promote their collective values" (2001, p. 114). This is a difficult question, because the goal which occurs in it is vague:

When we broaden the perspective to encompass our "collective values", the goal becomes much more nebulous. How does this relate to the actual wishes and preferences of the members of a society? How are we to integrate the preferences of different people? Can very different types of value be brought under a single measure? (2001, pp. 114-115)

A first possible way to deal with such questions is the objectivist one:

There are two very obvious ways of approaching the problems of the last paragraph. One is to suppose that whatever preferences people actually have, whatever they think about what it would be good for them to pursue, either individually or collectively, some ends are objectively worthy and there are objective relations among these ends. Call this general perspective objectivism about values (objectivism, for short). Objectivism can concede that there are many different kinds of values, some of them practical, some epistemic, some present, some future. I may even countenance human diversity, supposing some packages of good things are better for some people, different packages for other people. But objectivists think there's a right way of trading the epistemic against the practical - and, more generally, a right way of trading various different types of values for one another - a right way of balancing the present against the future, and a right way of integrating the objective interests of different individuals. (2001, p. 115).

\section{Kitcher formulates two objections against this objectivism:}

My doubts rest on the difficulty of divorcing what is good for a person from that person's own reflective preferences and the kindred problem of ignoring personal preferences in understanding the ways in which different distributions of goods across the stages of a person's life yield overall value. Further, I think that the general problem of understanding how to aggregate individual levels of well-being into a measure of collective welfare, in the ways objectivists propose, is extremely difficult. (2001, p. 116)

\footnotetext{
2 This phrase is taken literally from Bacon's book.
} 
Because of these objections, he chooses a subjectivist perspective:

Individual preferences should form the basis for our understanding of the personal good that inquiry (among other social institutions) is to promote. In moving from the individual to the measurement of value for the society, we should explicitly limit our discussions that honor certain democratic ideals. Hence my approach to the fundamental question, "What is the collective good that inquiry should promote?" will start from a subjectivist view of individual value (using personal preferences as the basis for an account of a person's welfare) and will relate the individual good to the collective good within a framework in which democratic ideals are taken for granted $(2001$, p. 116)

Kitcher is convinced that Bacon's idea is utopian: elitistic decision makers cannot know which research is good for the population for which they are responsible. He concludes from this that elitism (both the internal and the external variant) is a bad way to organise science policy.

3.3 I think that Kitcher's arguments against elitism are generally sound, but I will argue that they fail to show that elitism must be eliminated completely: they do not entail that all decisions about science policy should be taken democratically. To see this, it is important to distinguish different types of policy questions. The most general science policy questions a government or international organisation has to answer are (i) how much money will be spent on scientific research?, and (ii) how much of this money should go to research with practical significance, as opposed to research that has only epistemic significance? ${ }^{3}$ Kitcher's rebuttal of an objectivist perspective on values is a good argument to support the idea that these issues should be decided democratically, rather than in an elitist way (I will discuss this in more detail in Section 5). Let us assume that it has been (democratically) decided that $x \%$ of the budget for scientific research should go to projects with no practical significance (only epistemic significance), while the rest goes to research that has some practical significance. Kitcher's subjectivist perspective gives an argument for dividing the latter part if the budget in a democratic way among more specific domains and among topics within domains (this will also be discussed in more detail in Section 5). Here we confine ourselves to the $x \%$ which must be spent on research with only epistemic significance. It can be argued that an elitist procedure is the best way to distribute that money. I offer two arguments below. (3.4 and 3.5).

3.4 The first argument starts from natural human curiosity as implementation of epistemic significance. What are the consequences of invoking natural human curiosity as justification for doing and financing scientific research which has no practical significance? Human curiosity varies a lot across cultures and individuals. At first sight, this variety seems to constitute an argument for democratic decisions in the area of epistemically significant research. On closer inspection, this turns out not be true. The results of the research will only satisfy the curiosity of a group of scientists who are

3 To avoid confusion, I want to clarify my terminology. Because - as Kitcher rightly argues - practical and epistemic significance are often interwoven, we should in principle distinguish three categories of research: research with practical significance but without epistemic significance, research with both practical and epistemic significance (Kitcher uses the human genome project as an example for this category) and research with only epistemic significance (Kitcher mentions research with superconducting supercolliders as an example in this category). When I write "research with practical significance", I mean the union of the first two categories. 
familiar with the topic. Advanced scientific research will not satisfy the curiosity of the general public, because the general public does not understand what is written in scientific journals. Non-scientists can benefit from practically significant research because using the results does not require mastering the underlying theories. For instance, I can take aspirin and benefit from it without knowing anything about how it works. This kind of "detachment" is impossible with respect to curiosity. Note that I am not saying that the curiosity of non-scientists is not important or can be neglected: my claim is that science is not an appropriate instrument for satisfying this curiosity.

Under this assumption, the principle of subsidiarity comes into play. In a survey article on this principle, Andreas Føllesdal describes it as follows:

The "principle of subsidiarity" regulates authority within a political order, directing that powers or tasks should rest with the lower-level sub-units of that order unless allocating them to a higher-level unit would ensure higher comparative efficiency or effectiveness in achieving them. (1998, p. 190)

The sub-units can be territorial or functional (see Føllesdal 1998, p. 196). In the first case, it regulates the relation between levels in a federal state (e.g. states and the federal government in the USA; German Länder and the German Federal Republic) or an international political union (e.g. the member states of the EU versus the EU). In the second case, the sub-units are social groups without a specific territory. For instance, in many countries physicians and lawyers have their own professional organisation which develops a code of ethics and has institutes for enforcing it. If we assume that only scientists benefit from the result of epistemically significant research (because that research can only satisfy the curiosity of scientists) then one should allow scientists, as a sub-unit, to take their own decisions. This is not elitism, in the sense that it entails that scientists decide what is good for other people. It is democracy combined with subsidiarity: scientists who decide about what is good for themselves, without interference of outsiders who are no stakeholders.

Before I turn to my second argument, I want to mention an assumption that I have tacitly made. I assume that the class of "research which has only epistemic relevance" is not necessarily empty. Kitcher says that "in many cases though not in all, epistemic and practical interests are interwoven" (2001, p. 76; emphasis mine). The emphasised part of the quote is crucial. If epistemic and practical interests would always be interwoven, my criticism would be pointless because research which has only epistemic relevance would be impossible. However, examples of past research show it is possible. Whether or not it constitutes a large part of scientific research should be a democratic decision.

3.5 Invoking inborn or natural curiosity is not the only way to justify doing and financing scientific research that has no obvious practical significance. Another route is to claim that there are many serendipitous discoveries. Kitcher does not consider this possibility. I consider it here because it could be a different way to argue against elitism with respect to research that has only epistemic significance.

To make this route work, it is important to distinguish between pseudoserendipity and real serendipity:

I have coined the term pseudoserendipity to describe accidental discoveries of ways to achieve an end sought for, in contrast to the meaning of (true) serendipity, which describes accidental discoveries of things not sought for.

For example, Charles Goodyear discovered the vulcanization process for rubber when he accidentally dropped a piece of rubber mixed with sulfur onto a hot stove. For many years Goodyear 
has been obsessed with finding a way to make rubber useful. Because it was an accident that led to the successful process so diligently sough for, I call this a pseudoserendipitous discovery. In contrast, Georges de Mestral had no intention of inventing a fastener (Velcro) when he looked to see why some burs stuck tightly to his clothing. (Roberts 1989, p. x)

Another example of pseudoserendipity is Archimedes' famous accidental discovery - by stepping into a bath - of a way to measure to volume of irregularly shaped solids (Roberts 1989, p. 1-3). Pseudoserendipity, as defined by Roberts, means that a practically significant result which we have been looking for is obtained partially by accident. In order to justify research without clear practical significance, only real serendipity can be invoked. More specifically, we need real serendipity where the aim of the scientist is not practical at all. Roberts' book contains several examples of this kind of serendipity: besides Velcro, there is for instance the discovery of saccharin as a byproduct of purely theoretical research (p. 151) and the discovery of X-rays by Röntgen, who had no practical applications in mind (p. 139-143). Real serendipitous discoveries in which the scientist wanted to find something else of practical significance do not help us if we want to argue that it is worthwhile to spend money on research that has no clear practical value. For instance, William Perkin discovered the first artificial dye (mauve) while looking for a way to synthesize quinine, the malaria drug which at that time could only be obtained from the bark of the cinchona tree (see Roberts 1989, p. 6670). Such cases of serendipity do not help to justify research without practical value, because Perking aimed at finding something practically useful.

Let us now investigate the consequences for science policy of invoking real serendipity (of the right kind) as justification for doing and financing scientific research which has no practical significance. If we assume that it is impossible to judge in advance which prima facie practically useless research will in the end lead to practically significant results, then the heuristic value of research can only be established with hindsight. Considerations of heuristic value should have no place in policy decisions, because they fail to discriminate: everything can have serendipitous effects, and thus turn out to have heuristic value for practically significant results. Decisions about which practically non-significant research should be done and financed, should be made on the basis of formal criteria not on the basis the content. With formal criteria I mean criteria which guarantee that the research results in reliable knowledge, such as the capacities of the researchers and the methodological soundness of research proposals. Since scientists are experts in these formal criteria (for instance, they can judge the methodology proposed by other scientists) scientists should make those decisions. To put it differently, the serendipity perspective (as an argument for financing non-practically significant research) entails no restrictions on the content of scientific research. It only entails that our science policy must lead to reliable scientific results (no fraud, no bad procedures, ...). In order to ensure that, an elitist science policy (in Kitcher's sense) is probably the best option.

\section{Kitcher's arguments against vulgar democracy}

4.1 As already mentioned at the beginning of Section 3, Philip Kitcher distinguishes four forms of science policy: internal elitism, external elitism, vulgar democracy and enlightened democracy. This is how he characterises the third and fourth institutional arrangement, near the end of Chapter 10 of his book: 
A third, vulgar democracy, imagines that the decisions are made by a group that represents (some of) the diverse interests in the society with the advice from scientific experts. The fourth, enlightened democracy, supposes decisions are made by a group that receives tutoring from scientific experts and accepts inputs from all perspectives that are relatively widespread in the society: in effect, it fosters a condensed version of the process of ideal deliberation l've outlined (2001, p. 133)

At the beginning of Chapter 10 of his book, Kitcher gives a different characterisation of vulgar democracy:

There's a simple way to develop the idea that properly functioning inquiry -well-ordered science should satisfy the preferences of the citizens in the society in which it is practiced. Projects should be pursued just in case they would be favored by a majority vote. Call this "vulgar democracy". Vulgar democracy doesn't require actual voting. Rather it offers a standard against which we can assess rival schemes for deciding which endeavors are to be undertaken. The idea of calling together the citizenry to cast ballots on each occasion of decision is evidently absurd, but vulgar democracy is only committed to seeking social arrangements (committees of representatives, for example) that we might expect to do well at mimicking the outcomes of the expression of individual preferences. (2001, p. 117)

Kitcher rejects vulgar democracy. However, his argument against vulgar democracy is invalid under both characterizations he gives.

\subsection{Kitcher's argument against vulgar democracy is this:}

The most obvious deficiency, of course, lies in the fact that people's preferences are often based on impulse or ignorance and thus diverge from favoring what would be actually be good for them. Only a moment's reflection is needed to see that the most likely consequence of holding inquiry to the standard of vulgar democracy would be a tyranny of the ignorant, a state in which projects with epistemic significance would often be dismissed, perceptions of short-term benefits would dominate, and resources would be likely to be channeled toward a few "hot topics." Because these consequences plainly diverge from the promotion of well-being, vulgar democracy is a bad answer to our question. (2001, p. 117)

Is this argument valid under the second characterisation of vulgar democracy? If we use that definition, the core of Kitcher's argument is:

Any decision mechanism about science policy that aims at mimicking the majority vote, leads to tyranny of the ignorant.

Similar incompetence arguments have been given against universal suffrage for men (as opposed to only suffrage based on tax paid), suffrage for women, for blacks in SouthAfrica etc. Kitcher should have thought twice before joining this group. But more importantly: all these arguments turned out to be wrong after opponents lost the battle. Workers, women and black turned out to be competent voters. So under the second definition, the argument is not convincing.

Let us now look at the first definition. According to that characterisation, democratic decision-makers in a vulgar democracy receive advice from scientists. If the scientists do their job well, there is no reason to expect tyranny of the ignorant. So the argument that vulgar democracy leads to tyranny of the ignorant is not valid under this definition. A further problem with this characterisation is that the difference between vulgar and enlightened democracy becomes unclear: in vulgar democracy there is "advice" from 
scientists, in enlightened democracy there is "tutoring". That is the only difference in the definitions. If "tutoring" is just another word for "advice" (as some people may claim), there is no difference between vulgar and enlightened democracy. If tutoring means that the scientists educate the savage non-scientists, then enlightened democracy is elitism in disguise: only vulgar democracy is really democratic.

4.3 There is a third definition of vulgar democracy (one that Kitcher does not give) under which the argument is valid. If we define vulgar democracy as direct democracy in all decisions, then vulgar democracy indeed may lead to tyranny of the ignorant. But that is a very trivial result. Defenders of referenda and other forms of direct democracy usually see them as correction mechanisms in a parliamentary democratic system. Kitcher's argument against vulgar democracy in science policy is in fact an argument against complete direct democracy in science policy (i.e. against the idea that all decision in science policy should be taken by referenda) and in favour of representative democracy (with or without corrective referenda). But that looks like a straw man argument: it is very doubtful that anyone has ever proposed complete direct democracy in science policy.

To sum up: Kitcher's two characterisations of vulgar democracy do not result in a useful conceptual distinction. The third characterisation we considered faces the same problem. So it seems wise to give up the distinction.

\section{Outline of a democratic science policy}

How should science policy be organised? In this Section I present a brief outline. The first (and maybe most important question) in science policy is: how much of the money the state receives through taxes and other sources should go to scientific research? In a political democracy, this decision is - by definition - taken in a democratic way. It is an item in the yearly budget composed by the government and approved by the parliament. However, if we agree that the distinction between practical and epistemic significance makes sense (as mentioned at the beginning this chapter, my view on the aims of science are similar to Kitcher's, so I do think this distinction makes sense) the ideal situation is one in which the parliament explicitly decides how much money should go to research which has anticipated practical significance and research which has no anticipated practical significance. Such a decision is facilitated if the institutes that divide the money among researchers (cf. the second and third part of my proposal) are clearly distinguished. In Belgium, each university has a so-called "Bijzonder Onderzoeksfonds" (Special Research Fund) and a so-called "Industrieel Onderzoeksfonds" (Industrial Research Fund). The research financed by the latter one should result in "potentially application-oriented knowledge with an economic finality", while the first has no such restriction. The research it finances can have practical significance, epistemic significance or both. The money the funds distribute comes from the government. By allocating a certain amount of money to each type of fund, the government/parliament can influence the distribution between practically and epistemically significant research. However, the government/parliament should have complete control over this distribution, and that is only possible if there are no funds with a "mixed" task (i.e. no funds that finance both practically relevant research and research without immediate practical relevance). In the Belgian institutional arrangement, the Industrial Research Funds decide about a subset of practically relevant research (research that leads to the 
production of technological artefacts and is practically relevant through this production). The Special Research Funds decide about a wide variety of research ranging from practically relevant research that is not "materializable" into technological artefacts (e.g. research on the prevention of cancer, or research on global governance) to research without practical significance. This distribution of tasks is certainly not the optimal one.

The second part of my proposal is that decisions about research that is not practically significant should be taken by scientists only. My arguments for this can be found in Section 3.3 (subsidiarity) and 3.4 (serendipity). Of course, within scientific communities, there is no reason for further elitism: scientists should democratically decide about who becomes member of boards (consisting of scientists) who decide about research projects that have only epistemic significance.

I suppose that in many countries there is room for some or a lot of democratisation in this respect. For instance, the members of the board of the Special Research Fund at my own university are elected by their colleagues, while this is not the case for the members of the scientific committees of the Research Fund - Flanders (FWO) which functions at a regional level (multiple universities) rather than at a local level (one university).

The final part of my proposal is a plea for a democratisation of the decisions about practically significant research projects. The Belgian federal government finances research that relates to its policy (through a framework programme called "Action for supporting the strategic priorities of de Federal Government"). The regional Flemish government does the same through a number of centres for policy-relevant research ("Steunpunten voor beleidsrelevant onderzoek"). This is useful, and in principle also democratically organised (the democratically elected government decides what is done). However, such systems (which I assume to exist in many other countries too) have three obvious shortcomings from a democratic point of view. First, political parties that have representatives in the parliament but are not in the government are excluded from the decision process. This is problematic, because they should have the right to require research on certain topics, e.g. in order to prove that the policy of the government has failed in a certain domain. The second problem is that social movements which (unlike for instance environmentalists who can call on "green" parties) do not have a political counterpart are also excluded from the decision process. Third, democracy in these institutes is very indirect: the "will of the people" is represented by civil servants appointed by and reporting to the government (that there is representation is not a problem, but the chain of representations is very long). A really democratic science policy has to remove these shortcomings.

\section{References}

A. Føllesdal (1998) 'Subsidiarity', The Journal of Political of Philosophy, 6, 190-218.

C. G. Hempel (1965) Aspects of Scientific Explanation and other Essays in the Philosophy of Science. (New York: Free Press).

P. Kitcher (1993) The Advancement of Science (New York: Oxford University Press).

P. Kitcher (2001) Science, Truth and Democracy (New York/Oxford: Oxford University Press).

L. Laudan (1977) Progress and its Problems (London: Routledge).

R. M. Roberts (1989) Serendipity. Accidental Discoveries in Science (New York: John 
Wiley \& Sons). 


\section{Biographical note}

Erik Weber is professor in philosophy of science at Ghent University (UGent). Most of his research relates to general theories of causation and explanation, or to problems relating to causation and explanation in specific scientific disciplines (psychology, the biomedical sciences and the social sciences). He also works on the metaphysics of causation and on the application of non-classical logics in the philosophy of science. 